\title{
Alternative scheme for frequency response function measurement of experimental- analytical dynamic substructuring
}

\section{W. I. I Wan Iskandar Mirza, M. N Abdul Rani*, M. A Yunus, R. Omar, M. S Mohd Zin}

\author{
Structural Dynamics Analysis \& Validation (SDAV) \\ Faculty of Mechanical Engineering, Universiti Teknologi MARA (UiTM) Shah Alam, \\ 40450 Shah Alam, Selangor, Malaysia. \\ Phone: + 03-5543 5228 \\ *Email: mnarani@uitm.edu.my
}

\begin{abstract}
The accuracy of the predicted dynamic behaviour of an assembled structure using the frequency based substructuring (FBS) method is often found to be diverged from the experimental counterparts. The divergence which has become the paramount concern and major issue for structural dynamicists is because of the unreliable experimental frequency response function (FRF) data of the interfaces of substructures, arising from the limited resources of appropriate excitation points and accelerometer attachments in the vicinity of the interfaces. This paper presents an alternative scheme for FRF measurement of the experimental FRF data of substructures. In this study, an assembled structure consisting of two substructures were used, namely substructure A (Finite element model) and substructure B (Experimental model). The FE model of substructure A was constructed by using 3D elements and the FRFs were derived via the FRF synthesis method. Specially customised bolts were used to allow the attachment of accelerometers and excitation to be made at the interfaces of substructure B, and the FRFs were measured by using impact testing. Both substructures A and B were then coupled by using the FBS method and the coupled FRF was validated with the measured FRF counterparts. This work revealed that the proposed scheme with specially customized bolts has successfully predict the lower modes of the structure, specifically for the $1^{\text {st }}, 2^{\text {nd }}, 3^{\text {rd }}$ and $4^{\text {th }}$ modes.
\end{abstract}

Keywords: Frequency based substructuring, modal testing, structural dynamics.

\section{INTRODUCTION}

The understanding of the dynamic behaviour of engineering structures has always been a paramount consideration for structural engineering applications. In most cases, the structures are usually very complex and consist of a large number of components of which some of whose dynamic behaviour is very difficult to be determined by the finite element method [1, 2]. For the past few decades, the dynamic behaviour of an assembled structure consisting of several components, has been efficiently and economically predicted by using the dynamic 
substructuring methods [3-6]. One of the most popular dynamic substructuring methods used is frequency based substructuring (FBS).

This method has the capability and versatility to calculate the FRF of an assembled structure (coupled FRF) by combining the analytical, derived and measured, FRFs from the substructures. The equations for the coupled FRF are derived by balancing the forces and enforcing continuity at the interface which is thoroughly explained in [7]. For an instance, Law, Rentzsh and Ihlenfeldt [8-10] predicted the dynamic response of an operating machining tool by coupling the FRF of an operating machine with other several substructures via the FBS method. Another striking example is that the FBS method was used for predicting the dynamic behaviour of the isolation system for an operating machinery as demonstrated in $[11,12]$. All the examples have demonstrated a strong link between efficiency and economics of the FBS method in the use of predicting the dynamic behaviour of a complex structure.

Attempts to use the FBS method for combining the experimental results with the numerical counterparts have been made by structural dynamicists for decades, however, the attempts have often found to be unsuccessful[13, 14]. The essential issue lies in the FBS method used in the preparation of experimental work as highlighted in [15]. The basic theory of the FBS method is that the FRF of all degrees of freedom (DOFs) at the interface connection is required for the coupling process [16] but measuring accurately all the translational and rotational FRFs at the interfaces of substructures is very challenging and problematic $[17,18]$. A few approaches have been proposed to improve the FBS method such as the transmission simulator method [19], the variability improvement of key inaccurate node groups (VIKING) [20], inverse dynamic substructuring [21] and modal expansion methods [22, 23]. In addition, the use of rotational accelerometer has been used recently to measure the rotational responses which can be used to improve the predicted dynamic behaviour via FBS method [23, 24].

In some cases, the position or design of the interface of a structure itself is almost impossible to be excited in all directions. For instance, when the interface is located at the centre of a large flat span structure. This sort of scenario was discussed at length in [25]. This situation has instigated a notion to the author to introduce an alternative approach for measuring the FRFs at the interface by attaching a specially customized bolt, which allows the dynamists to directly excite the interface of a structure [26]. This approach was slightly different to the transmission simulator approach, where the size and the mass of the bolt is very small in hence the additional decoupling process is needless.

This study is developed an alternative scheme for FRF measurement of experimentalanalytical dynamic substructuring using the FBS method. Two identical beam substructures are used to analyse the capability of the proposed scheme for the FBS method. The specially customized bolts are used for the excitation and accelerometer attachment to the test substructure (substructure B). The coupled FRF between both substructures are then compared with the actual measured FRF of the assembled structure for evaluation purposes.

\section{Physical Test Structure}

The applicability of the proposed alternative scheme for FRF measurement for FBS is demonstrated on a simple steel beam structure which consists of two rectangular crosssection steel beams, namely substructures A (FE derived FRF) and B (Experimental FRF). Both substructures were $380 \mathrm{~mm}$ long, $45 \mathrm{~mm}$ wide and $6 \mathrm{~mm}$ of thickness, and then combined 
together by two bolted joints as shown in Figure 1. This simple configuration allowed an initial study of the efficiency and applicability of the proposed scheme for FRF measurement for a simple structure such as beams as demonstrated in the previous work [27-29]. The excitation frequency of interest for this case study was between 0 to $2000 \mathrm{~Hz}$.

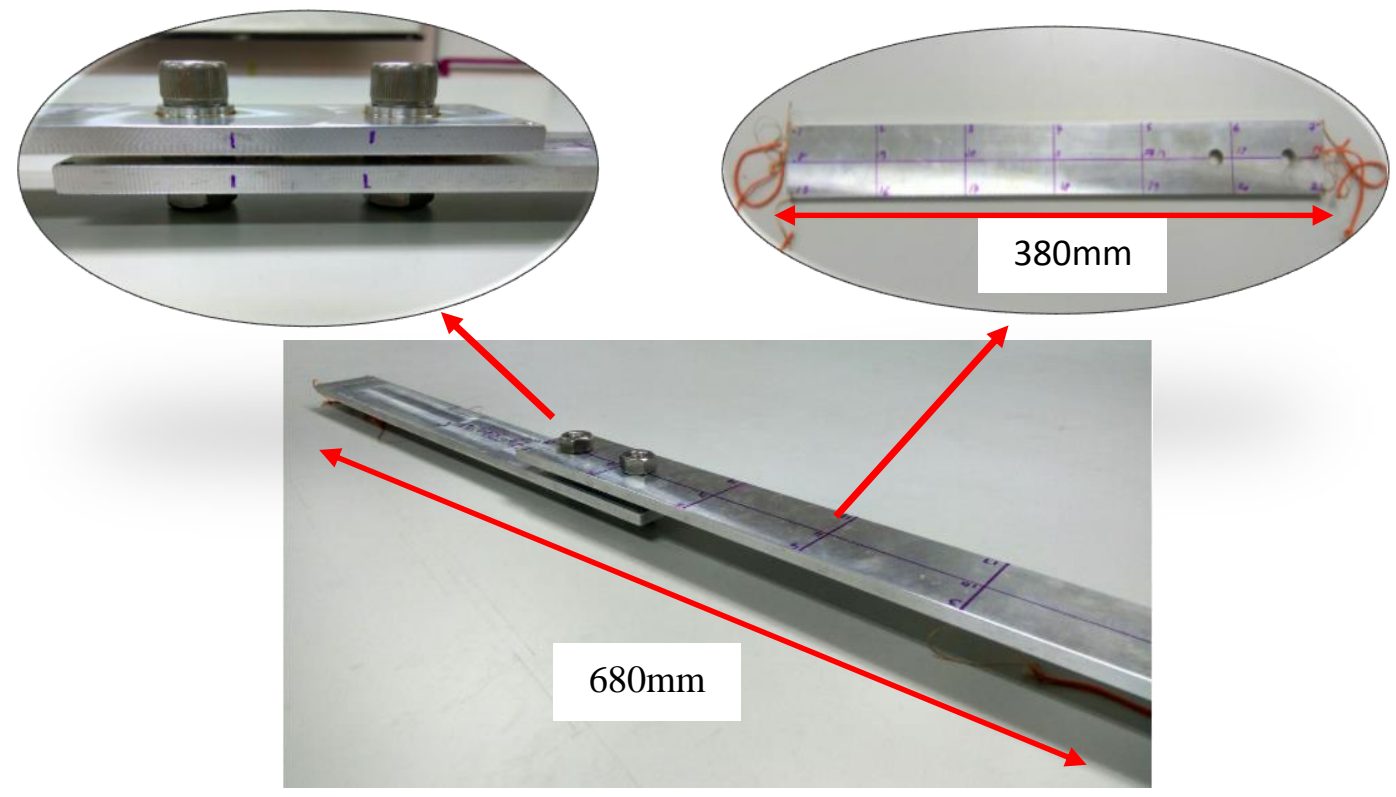

Figure 1. Test structure

\section{Description of specially customised bolts}

The basic theory of the FBS method describes that all the FRF matrix at the interface must be included for ensuring the successful implementation of FRF coupling [7]. In order to obtain a complete FRF matrix, all the translational and rotational responses must be measured [26]. Specially designed bolts are introduced to ensure that the accelerometer attachment and excitation at the interfaces can be successfully performed. The bolts are made of hardened steel and designed with a $12 \times 12 \times 12 \mathrm{~mm}$ cube head and M10 full thread as shown in Figure 2(a). The specially customised bolts are attached to substructure B as shown in Figure 2(b). 


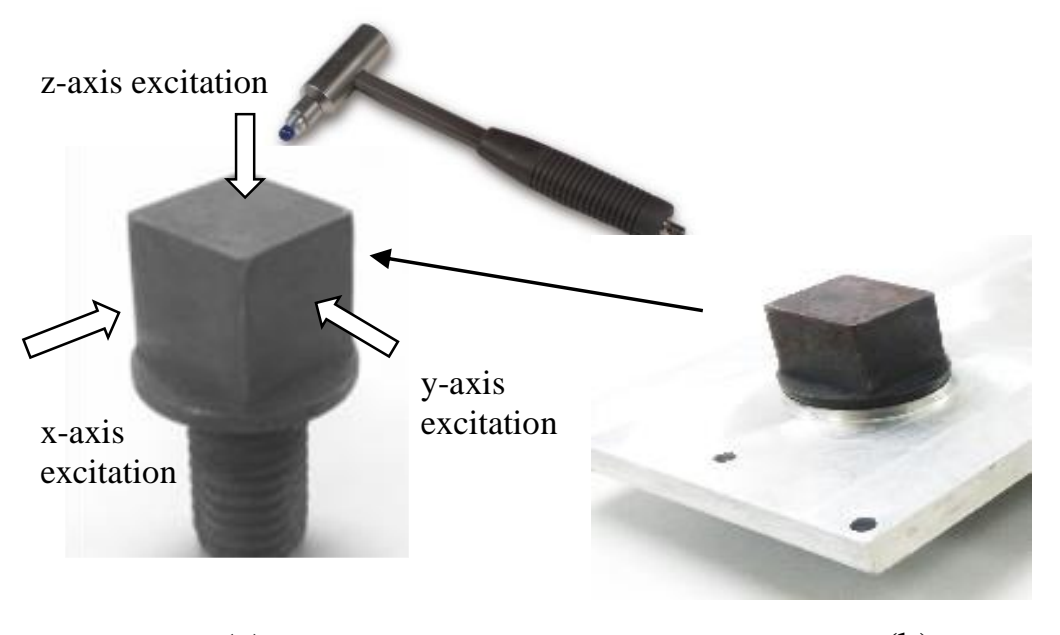

(a)

(b)

Figure 2. (a) Specially customised bolt with cube head (b) Attachment of specially customised bolts to substructure B

\section{FINITE ELEMENT MODELLING FOR SUBSTRUCTURE A}

As stated in the introduction section, the interface FRFs of substructure A were derived numerically by using the FRF synthesis method based on calculated modes. For this method, the synthesized FRF matrix $\mathrm{H}_{\text {syn }}\left(\omega_{\mathrm{k}}\right)$ and mode shapes are expressed by:

$$
\mathrm{H}_{\mathrm{syn}}\left(\omega_{\mathrm{k}}\right)=\sum_{i=1}^{N} \frac{\{\varnothing\}_{i}\{\varnothing\}_{i}^{T}}{\left(\omega_{n_{i}}^{2}-\omega_{k}^{2}\right)+j 2 \xi_{i} \omega_{k} \omega_{n_{i}}}
$$

where $N$ is the number of calculated modes, $\{\varnothing\}_{i}$ is the $i$ th mass normalised mode shapes, $\omega_{n_{i}}$ is $i$ th natural frequency and $\xi_{i}$ is the $i$ th modal damping ratio. The substructure A was discretised into 26622 3D elements and the properties were defined as follows; density = $7850 \mathrm{~kg} / \mathrm{m}^{3}$, Young's modulus $=70 \mathrm{GPa}$ and Poisson's ratio $=0.33$. Since only $3 \mathrm{D}$ elements were used for the modelling, therefore, only the translational FRFs were synthesized and used in the process of experimental-analytical FRFs coupling. Based on the experimental modal analysis from the next section of this paper, the synthesized FRFs were extracted up to $4000 \mathrm{~Hz}$, which are two times more than the frequency of interest of the assembled structure to minimise the truncation errors.

\section{EXPERIMENTAL SET UP FOR EXPERIMENTAL SUBSTRUCTURE}

The FRFs of substructure B were measured by using an impact testing method by referring to the previouse studie $[30,31]$. The substructure was tested under free-free boundary conditions to minimise the effect of constraint to the structure. The interfaces of substructure $\mathrm{B}$, which are in the vicinity of the two through holes, were used for the attachment of the two specially customised bolts to allow the impact excitation in $\mathrm{x}, \mathrm{y}$ and $\mathrm{z}$ directions. Two 
$100 \mathrm{mv} / \mathrm{g}$ tri-axial accelerometers were attached to the interfaces in order to measure the translational responses in all directions as shown in Figure 3. The frequency bandwidth for the measured FRFs was also between $0-4000 \mathrm{~Hz}$. The measured FRFs were compared with the synthesized FRFs, and the results of the comparison are discussed in the discussion section.

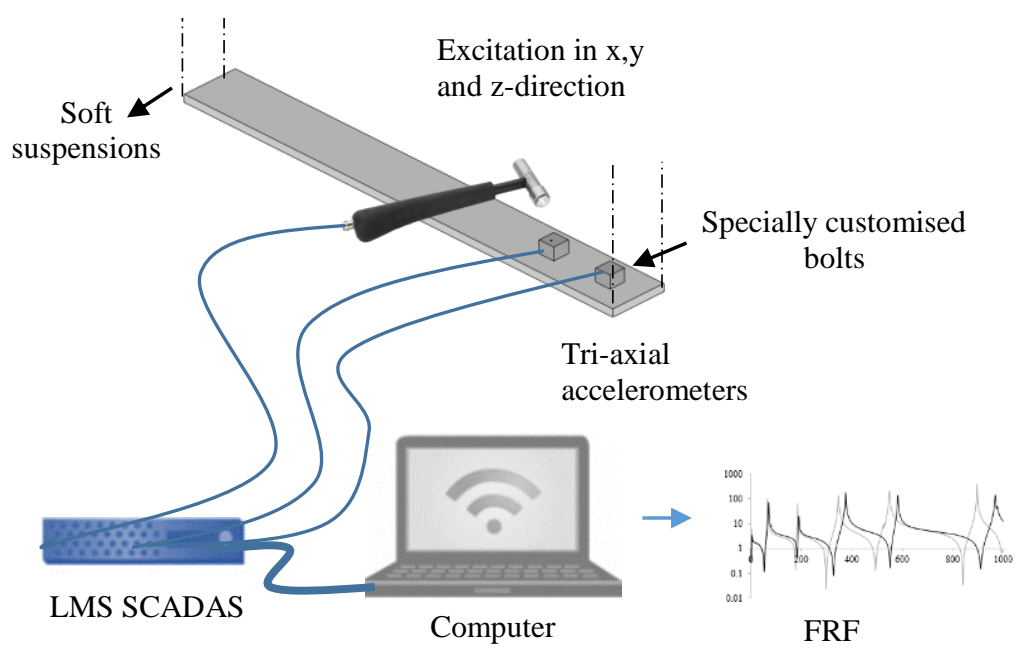

Figure 3. Experimental set-up for substructure B

The same method and procedure were used to measure the FRFs at the interface of the assembled structure consisting of substructures A and B as shown in Figure 4. The frequency bandwidth used for the assembled structure was between $0-2000 \mathrm{~Hz}$.

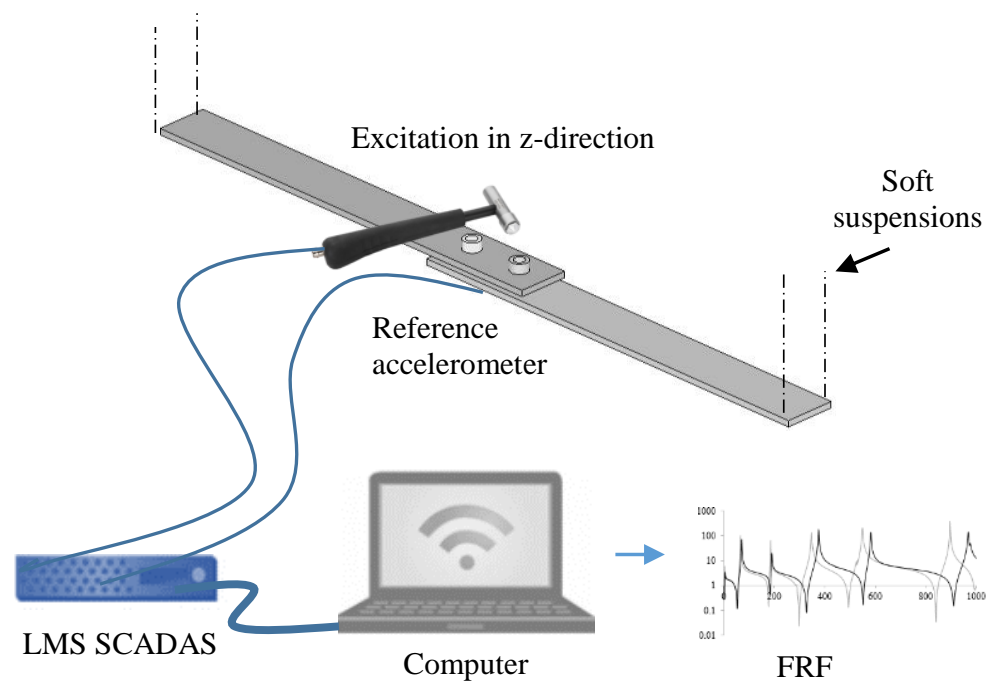

Figure 4. Experimental set-up for assembled structure. 


\section{FBS METHOD}

The assembled structure (S) consisting of substructures (A) and (B) in which the DOFs are classified either as internal or coupling DOFs. The internal DOFs of both substructures are represented as subscript $a$ and $b$, while the connection DOFs are described as subscript $c$. Both substructures are independent of one another before the coupling process is carried out. The c-DOFs must be the same for both substructures. The dynamic behaviour for each substructure in the frequency domain is:

$$
\mathbf{X}_{\mathrm{n}}=\mathbf{H}_{\mathrm{nn}} \mathbf{F}_{\mathrm{n}}
$$

where $\mathbf{X}_{\mathrm{n}}$ is the complex displacement matrix, $\mathbf{H}_{\mathrm{nn}}$ is the complex admittance matrix in the form of displacement, force $\mathbf{F}_{\mathbf{n}}$ is the applied force vector and the subscript $n$ is the total number of DOFs for each substructure. Now, let the superscript $S$ represent the coupled system where both substructures A and B are connected at DOFs $\mathrm{c}$. The rigid connections between substructures $\mathrm{A}$ and $\mathrm{B}$, compatibility implies that

$$
\mathbf{X}^{\mathrm{A}}{ }_{\mathrm{c}}+\mathbf{X}^{\mathrm{B}}{ }_{\mathrm{c}}=\mathbf{X}^{\mathrm{S}}{ }_{\mathrm{c}}
$$

and the force equilibrium requires that

The FRFs of the system can be defined as

$$
\mathbf{F}^{\mathrm{A}}{ }_{\mathrm{c}}=\mathbf{F}^{\mathrm{B}}{ }_{\mathrm{c}}=\mathbf{F}^{\mathrm{S}}
$$

$$
\left\{\begin{array}{l}
\mathbf{X}^{\mathrm{s}}{ }_{\mathrm{a}} \\
\mathbf{X}^{\mathrm{s}}{ }_{\mathrm{c}} \\
\mathbf{X}^{\mathrm{s}}{ }_{\mathrm{b}}
\end{array}\right\}_{\mathrm{n}}=\left[\begin{array}{lll}
\mathbf{H}^{\mathrm{s}}{ }_{\mathrm{aa}} & \mathbf{H}^{\mathrm{s}}{ }_{\mathrm{ac}} & \mathbf{H}^{\mathrm{s}}{ }_{\mathrm{ab}} \\
\mathbf{H}^{\mathrm{s}}{ }_{\mathrm{ca}} & \mathbf{H}^{\mathrm{s}}{ }_{\mathrm{cc}} & \mathbf{H}^{\mathrm{s}}{ }_{\mathrm{cb}} \\
\mathbf{H}^{\mathrm{s}}{ }_{\mathrm{ba}} & \mathbf{H}^{\mathrm{s}}{ }_{\mathrm{bc}} & \mathbf{H}^{\mathrm{s}}{ }_{\mathrm{bb}}
\end{array}\right]\left\{\begin{array}{c}
\mathbf{F}^{\mathrm{s}}{ }_{\mathrm{a}} \\
\mathbf{F}^{\mathrm{s}}{ }_{\mathrm{c}} \\
\mathbf{F}^{\mathrm{s}}{ }_{\mathrm{b}}
\end{array}\right\}
$$

The equation above can be derived to obtain the coupled FRF. More detailed information regarding the derivation and explanation is available in $[32,33]$. The derived FRFs from the FE model of substructure A and FRFs measured from substructure B were coupled by using a rigid type of coupling. The frequency bandwidth was set between $0-2000 \mathrm{~Hz}$ and the coupled FRF was compared with the measured counterpart for the validation purposes.

\section{RESULTS AND DISCUSSION}

The accuracy of the predicted dynamic behaviour by using FBS method is highly dependent on the sufficient FRF in all DOFs at the coupling interfaces. The attempts to exclude one of the degrees of freedom during the process of coupling has usually led to completely different results [25]. Therefore, in order to obtain an accurate FRF prediction via the FBS method, all the DOFs at the interfaces need to be extracted and coupled. In this study, specially customised bolts attached to the two through holes of substructure B as shown in Figure 2(b) were used for the measurement of interface FRFs of the substructure. In order to validate the applicability of the proposed FRF measurement scheme, the measured interface FRFs of the substructure are validated with the FRFs derived from the FE model. The comparisons of the FRFs are presented in Figures 5, 6, 7 and 8 respectively. 


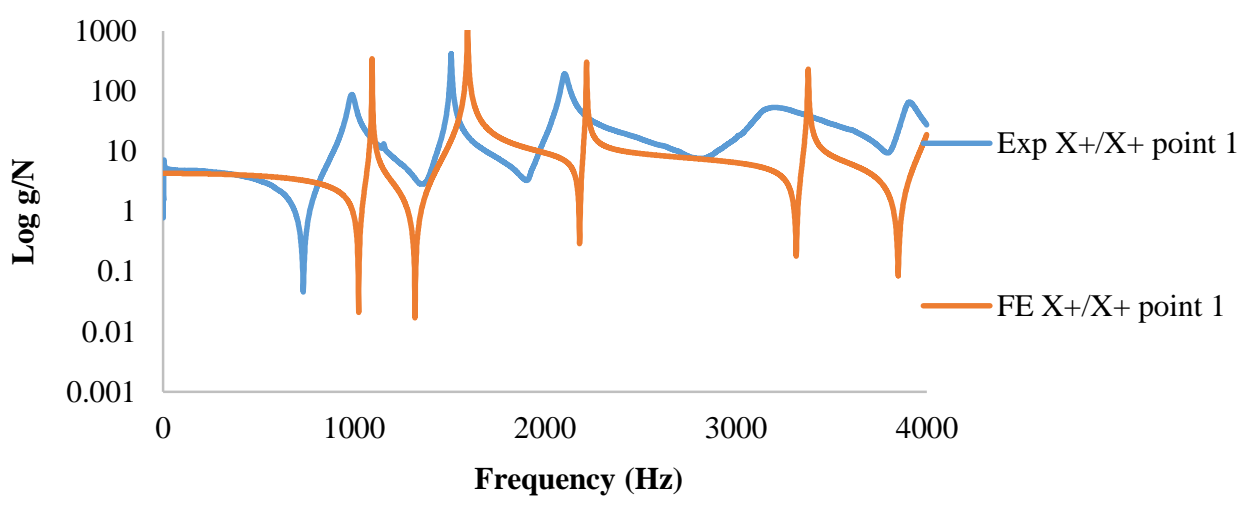

Figure 5. The comparison of the measured and FE FRF in $\mathrm{x}$ direction

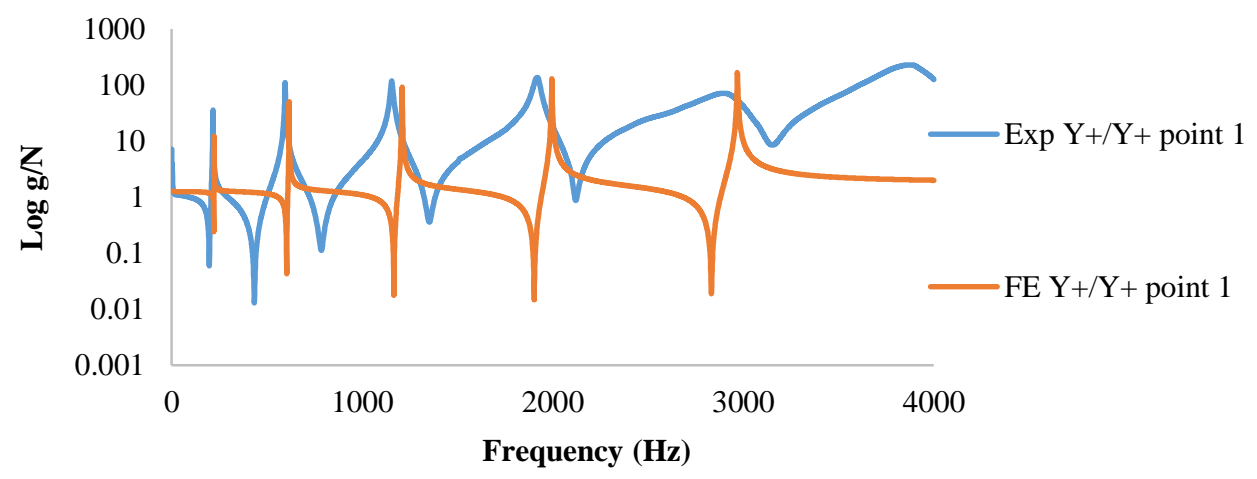

Figure 6. The comparison of the measured and FE FRF in y direction

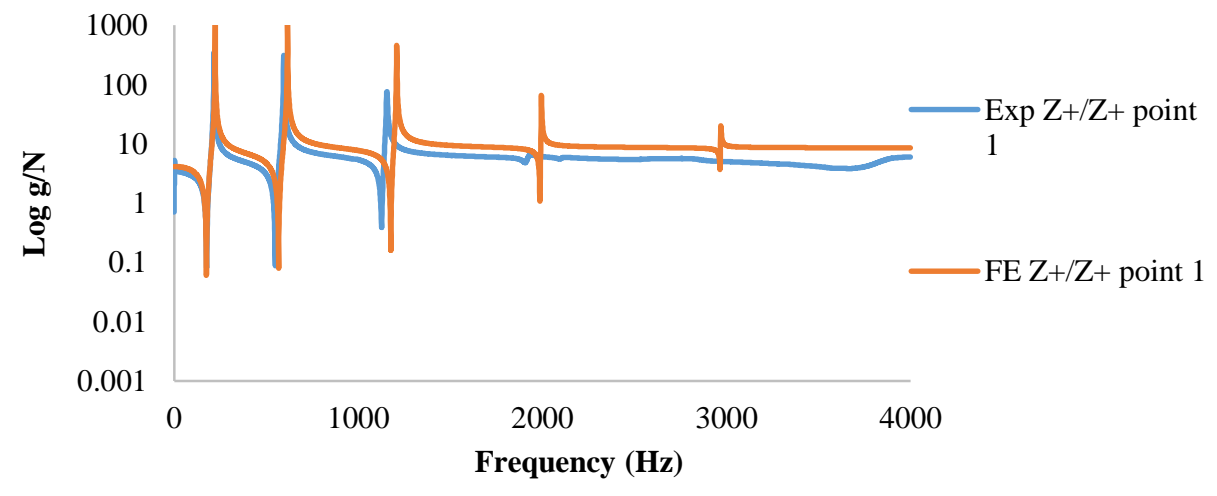

Figure 7. The comparison of the measured and FE FRF in $\mathrm{z}$ direction 


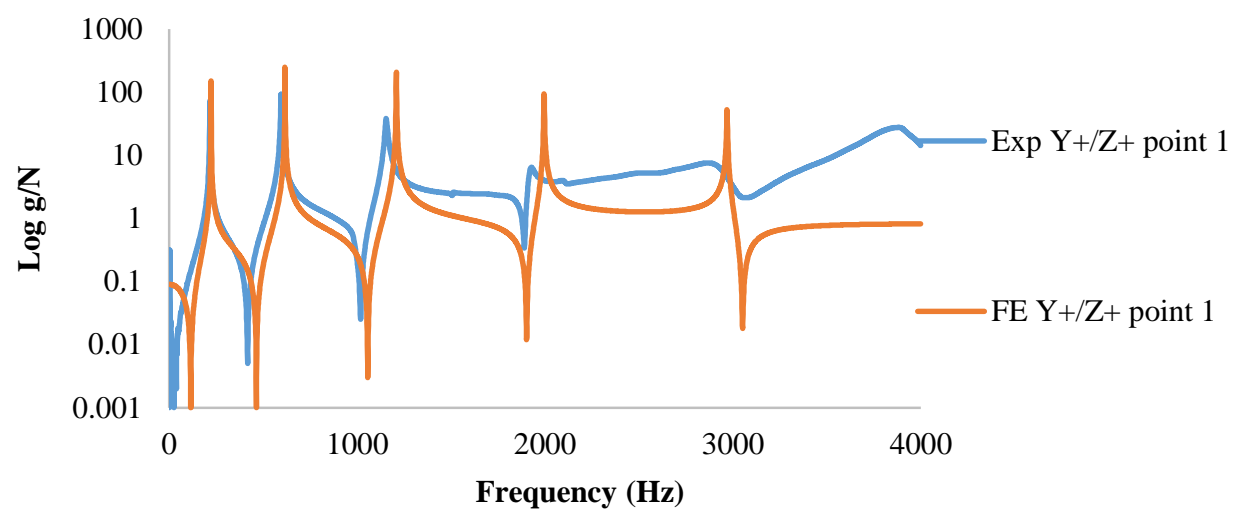

Figure 8. The comparison of the measured and FE FRF in cross-axis response between y and $\mathrm{z}$ directions.

From the figures presented (Figure 5,6,7 and 8), it can be clearly seen that the pattern and amplitude of the resonance as well as anti-resonance of the measured FRF are almost identical with the synthesized FE FRF in $\mathrm{z}$ direction as shown in Figure 7. It also can be observed that the cross-axis FRF between $y$ and $\mathrm{z}$ directions is in relatively good agreement with the FEFRF, especially for the lower frequency as depicted in Figure 8. However, the measured FRFs in $\mathrm{x}$ and $\mathrm{y}$ directions are incapable of matching well with the FE counterparts, specifically for the anti-resonances of the high frequency. However, the correlations between the measured and FE FRFs in $\mathrm{x}$ and y directions as illustrated in Figures 5 and 6 were found to be poor, a result which must probably be attributed to suspension movement effects (dominated by $\mathrm{z}$ direction). In addition, the mode shapes of the substructure are more noticeable in $\mathrm{z}$ direction. The sequence of events has led to the measured FRFs in $\mathrm{x}$ and $\mathrm{y}$ directions for the higher frequency becoming slightly inaccurate.

The FBS method was employed to predict the FRF of the complete assembled structure by coupling the measured FRFs of substructure B and FE FRFs of substructure A. The comparison between the coupled FRF obtained from the FBS method and the measured FRF of the assembled structure is presented in Figure 9. It was found that there are six modes of the measured FRF within the frequency bandwidth between $0-2000 \mathrm{~Hz}$. This achievement shows that all the six modes have been successfully calculated via the FBS method. Therefore, it is imperative to note that the proposed FRF measurement scheme offers a great capability in both enhancement and improvement to the current interface FRF measurement technique for the FBS method. 


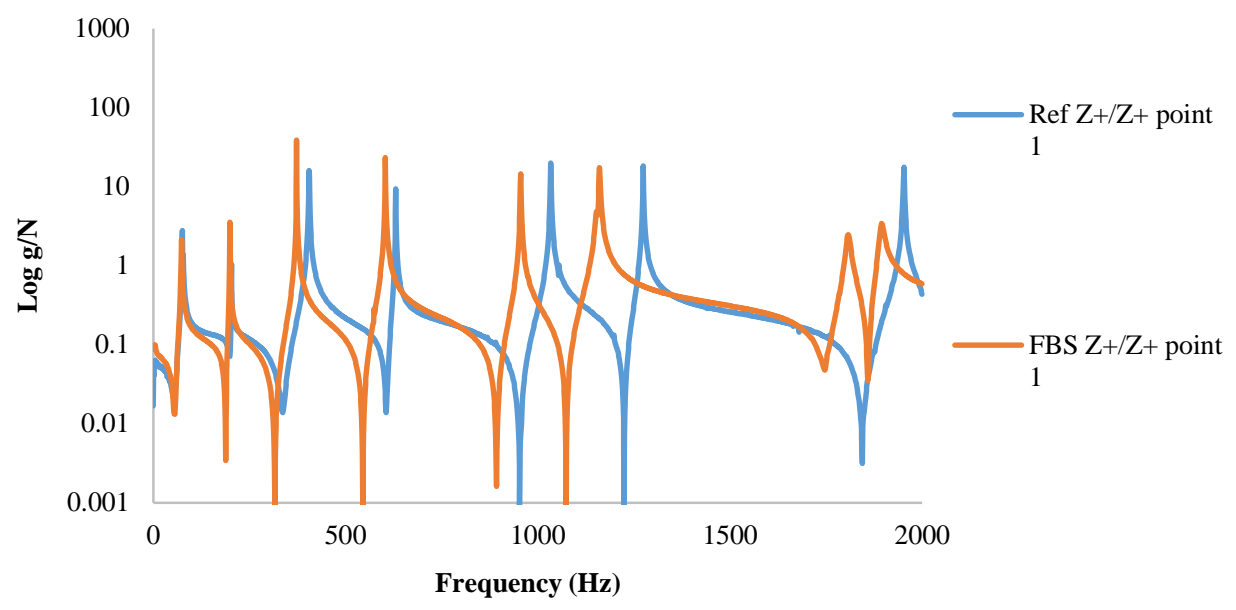

Figure 9. The comparison of two sets of the FRFs of the assembled structure obtained from the FBS method and from the experiment.

The relationship shown in Figure 9 indicates that there is a good match between the first and second resonant frequencies obtained from the FBS method and experimental counterparts. However, it is easily seen that the predicted FRF exhibits some quite significant differences in its resonance frequencies as the frequency increases. The comparison of the FRF reveals that the use of the specially customised bolts for the measurement of the interface FRFs of a substructure is more suitable for low resonant frequencies. Based on engineering judgement and observation, the discrepancies are most likely attributed to the effect of low accuracy of FRFs in $\mathrm{x}$ and $\mathrm{y}$ directions as mentioned before. In addition, the additional masses from the specially customised bolts have shifted more modes towards the low frequency segment. Furthermore, the discrepancies between the measured and coupled FRF might be due to invalid assumptions about the model properties of finite element models and the exclusion of rotational FRFs [33, 34].

\section{CONCLUSIONS}

The applicability of the proposed FRF measurement scheme by using specially customised bolts for the measurement of the interface FRFs of steel beam substructure is presented. All the translational FRFs at the interface of substructure B were successfully measured using the proposed measurement scheme. The $1^{\text {st }}, 2^{\text {nd }}, 3^{\text {rd }}$ and $4^{\text {th }}$ resonance peaks were accurately predicted by using the presented method. This achievement suggests that the FBS method has been successfully used for coupling and predicting experimental and analytical dynamic behaviour of an assembled structure, specifically for the lower modes. Therefore, it is worth noting that the proposed scheme has a great capability in both enhancement and improvement in the quality of measurement of the interface FRFs of substructures, especially for a complex structure with a large number of substructures where the measurement of the interface FRFs is usually very problematic and challenging. 


\section{ACKNOWLEDGEMENTS}

The authors gratefully indebt the Malaysian Ministry of Higher Education for providing financial support for this study through the fundamental research grant scheme (FRGS) (600RM1/FRGS 5/3 (96/2016). The authors also would like to express their upmost appreciation to Mr David Starbuck and Dr Siti Akmar Abu Samah for their advice, support and suggestions in this research.

\section{REFERENCES}

[1] Yunus MA, Rani MNA, Ouyang H, Deng H, James S. Identification of Damaged Spot Welds in a Complicated Joined Structure. Journal of Physics: Conference Series, 2011; 305: 012057.

[2] Rani MNA, Ouyang H, Yunus MA, Aminudin BA. Model Updating for a Thin Plate Structure. In: 20th International Congress on Sound and Vibration 2013, Bangkok, pp. 1138-1145; 2013.

[3] Rani MNA, Stancioiu D, M, Yunus MA, Ouyang H, Deng H, James H. Model Updating for a Welded Structure Made from Thin Steel Sheets. Applied Mechanics and Materials,2011; 70: 117-122.

[4] Seijs MVVD, Klerk DD, Rixen DJ. General framework for transfer path analysis: History, theory and classification of techniques. Mechanical Systems and Signal Processing, 2016; 68; 217-244.

[5] Rixen DJ, Valk VD. An Impulse Based Substructuring approach for impact analysis and load case simulations. Journal of Sound and Vibration, 2013; 332(26): 7174-7190.

[6] Valk VD, Rixen DJ. An Impulse Based Substructuring method for coupling impulse response functions and finite element models. Computer Methods in Applied Mechanics and Engineering, 2014; 275: 113-137.

[7] Klerk DD, Rixen DJ, Voormeeren SN. General Framework for Dynamic Substructuring: History, Review and Classification of Techniques. AIAA Journal, 2008; 46(5): 1169-1181.

[8] Law M, Rentzsch H, Ihlenfeldt S. Predicting mobile machine tool dynamics by experimental dynamic substructuring. International Journal of Machine Tools and Manufacture, 2016; 108: 127-134.

[9] Law M, Ihlenfeldt S. A frequency-based substructuring approach to efficiently model position-dependent dynamics in machine tools. In: Proceedings of the Institution of Mechanical Engineers, Part K: Journal of Multi-body Dynamics, 2015; 229(3): 304317.

[10] Law M, Rentzsch H, Ihlenfeldt S, Putz M. Application of Substructure Decoupling Techniques to Predict Mobile Machine Tool Dynamics: Numerical Investigations. Procedia CIRP, 2016; 46: 537-540.

[11] W. Peng. FRF-Based Substructure Technique for Modelling Machinery Isolation System. In: The 21 st International Congress on Sound and Vibration, Beijing, pp. 13$17 ; 2014$.

[12] Guo R, Zhou SQ, Wang MJ, Qiu S. Dynamic modeling and simulation of a two-stage series-parallel vibration isolation system. Advances in Mechanical Engineering, 2016; 
8(8): 1-19.

[13] Voormeeren SN, Klerk DD, Rixen DJ. Uncertainty quantification in experimental frequency based substructuring. Mechanical Systems and Signal Processing, 2010; 24(1): 106-118.

[14] Mirza WIIWI, Rani MNA, Yunus MA, Omar R, Zin MSM. Frequency Based Substructuring Method for the Investigation of the Dynamic Behaviour of a Beam Structure. Journal of Mechanical Engineering, 2017; 4(3): 142-154.

[15] Mayes R, Hunter PS, Simmermacher TW. Combining Lightly Damped Experimental Substructures with Analytical Substructures. In: International Modal Analysis Conference XXVI, Orlando, Florida, 2008.

[16] Urgueira VPA. Dynamic Analysis of Coupled Structures Using Experimental Data Techniques, PhD Thesis: 1989.

[17] Ewins DJ, Liu W. The Importance Assessment of RDOF in FRF Coupling Analysis. Imac Xvii, 1999; 2: 1481-1487.

[18] Peeters P, Manzato S, Tamarozzi T, Desmet W. Reducing the impact of measurement errors in FRF-based substructure decoupling using a modal model. Mechanical Systems and Signal Processing, 2018; 99: 384-402.

[19] K. C. Konjerla. FRF Based Experimental - Analytical Dynamic Substructuring Using Transmission Simulator, PhD Thesis: 2016.

[20] Nicgorski D, Avitabile P. Conditioning of FRF measurements for use with frequency based substructuring. Mechanical Systems and Signal Processing, 2010; 24(2): 340351.

[21] Ambrogio DW, Fregolent A. Inverse dynamic substructuring using the direct hybrid assembly in the frequency domain. Mechanical Systems and Signal Processing, 2014; 45(2): 360-377.

[22] Tol Ş, Özgüven HN. Dynamic characterization of bolted joints using FRF decoupling and optimization. Mechanical Systems and Signal Processing, 2015; 54: 124-138.

[23] Drozg A, Čepon G, Boltežar M. Full-degrees-of-freedom frequency based substructuring. Mechanical Systems and Signal Processing, 2018; 98: 570-579.

[24] Dumont M, Kinsley M. Rotational Accelerometers and Their Usage in Investigating Shaker Head Rotations. Sensor and Instrumentation, 2016; 5: 85-92.

[25] Manzato S, Risaliti E, Napoli C, Tamarozzi T, Peeters B. A Review of FrequencyBased Substructuring Methods and Their Applicability to Engineering Structures. In: Proceeding of International Conference of Structural Engineering Dynamics (ICEDyn), 2015.

[26] Mirza WIIWI, Rani MNA, Ayub MA, Yunus MA, Omar R, Zin MSM. Innovative FRF measurement technique for frequency based substructuring method. In: AIP Conference Proceeding, pp. 020010; 2018.

[27] Williams A, Chipman C, Avitabile P. Modal and frequency based substructuring using rotational DOF conidetations. In: International Modal Analysis Conference XXVI, Orlando, Florida, 2008.

[28] Allen MS, Mayes RL. Comparison of FRF and Modal Methods for Combining Experimental and Analytical Substructures. In: International Modal Analysis Conference XXV, Orlando, Florida 2007.

[29] Bakhtiari-Nejad F, Khorram A, Rezaeian M. Analytical estimation of natural frequencies and mode shapes of a beam having two cracks. International Journal of 
Mechanical Sciences, 2014; 78: 193-202.

[30] Lim TC, Li J. A Theoretical and Computational Study of the Frf-Based Substructuring Technique Applying Enhanced Least Square and TSVD Approaches. Journal of Sound and Vibration, 2000; 231(4): 1135-1157.

[31] Mirza WIIWI, Rani MNA, Othman MH, Kasolang S, Yunus MA. Reduced order model for model updating of a jointed structure. Journal of Engineering and Applied Sciences, 2016; 11; 2383-2386.

[32] Omar R, Rani MNA, Yunus MA, Isa MAA, Mirza WIIWI, Zin MSM, Roslan L. Investigation of Mesh Size Effect on Dynamic Behaviour of an Assembled Structure with Bolted Joints using Finite Element Method. International Journal of Automotive and Mechanical Engineering, 2018; 15(3): 5695-5708.

[33] Sani MSM, Nazri NA, Rani MNA, Yunus MA. Dynamic analysis of I cross beam section dissimilar plate joined by TIG welding. In: AIP Conference Proceedings, pp. 020086; 2018.

[34] Rani MNA, Kasolang S, Othman MH, Yunus MA, Mirza WIIWI. Finite Element Modelling and Modal Based Up- Dating for The Dynamic Behaviour of a Laser Spot Welded Structure. In: 23rd International Congress on Sound and Vibration: From Ancient to Modern Acoustics, Athens, Greece, 2016. 